\title{
Design and Application of Children's Entertainment Education Software in Preschool Education
}

\author{
https://doi.org/10.3991/ijet.v13i07.8809 \\ Xicai Li \\ Weinan Normal University, Shaanxi, China \\ xicaili2635@aliyun.com
}

\begin{abstract}
The current preschool education children's educational software mostly ignores the preschool children's psychological characteristics and rigidly combines the educational and entertainment nature of the game, which affects the learning effect of preschool children. Based on the psychological characteristics of preschool children, the characteristics of preschool children's demand for computer games were deeply analyzed. In addition, the preschool children's entertainment software was designed and developed. The game was built according to the system elements and design principles of the educational games, and the appropriate kindergarten curriculum content was selected so that preschool children can be substituted and truly entertained. The practice showed that the preschool children's educational software captured the psychological characteristics of preschool children. It is concluded that the software effectively promotes preschool children to obtain knowledge in a relaxed gaming environment and improves the learning effect of preschool children.
\end{abstract}

Keywords-Preschool education; children; educational software

\section{Introduction}

Children are growing infiltrated in the media environment and accompanied by games in surprises, fantasies, excitement and interests. Children's growth has been impacted by new technology and new media. The impact of computer games on children cannot be ignored.

The traditional kindergarten teaching method has many drawbacks. For instance, the teaching method is single and most of the teaching time is for all children. As a result, it cannot well develop young children's personal class capacity that is small, and it cannot meet the needs of each child and so on. In recent years, with the popularity of computer games, many game developers and preschool teachers have begun to realize that if they can use the advantages of computer games to extract their effective learning models, scientific design, effective organization to the field of preschool education, it has special results that the traditional game teaching for preschool children is difficult to achieve. The knowledge of preschool teaching is simple and imaged, and it has a certain component of the game itself. It is very suitable for making computer games, and the teaching and game can be better combined. 
A large number of survey data show that nowadays a lot of computer games for preschool children are directly from abroad, lacking localization research. In addition, many computer games for preschool children are commercial operation, and there are many disadvantages so that parents and preschool teachers do not dare to apply computer games to preschool easily in the study of children. So, what kind of computer game software is the requirement of preschool children and how to design the educational game software that promotes the healthy growth of preschool children is a common concern for young educators and parents at home and abroad.

Preschool education games based on preschool education content do not include all contents, nor is it necessary or impossible to achieve. It is the real purpose of designing and developing preschool education games to screen out appropriate content of preschool education and show it in some form of games. To achieve this goal, we need to think about the contents of preschool education and the way of computer games at present.

The life of preschool children should be firstly to be happy, to learn knowledge in a bright and happy virtual world, and to gradually increase wisdom and cultivate interest in the process of interaction, which is the purpose of our design of preschool education game software. This article focuses on the design and development of preschool children's educational games. It aims to explore the guiding theory and methods of the design and development of preschool children's educational games, and to dig out the inherent laws of the design of preschool children's educational games.

\section{$2 \quad$ Literature review}

In 2014, Boyd proposed the four stage of children's computer game design. The first step is to learn the general situation and to construct the user model, so that the materials and methods of language learning in the digital game are most suitable for the potential users, that is, the personal characteristics of preschool children. The second step is to focus on the establishment of the teaching field. In contains the three prominent sources of compliance guidelines in the field of teaching, the preschool syllabus of the Education Committee legislation, language combination, and the information obtained by the selected school plan sampling survey questionnaire. The third step is the interfaces of specific types and interaction between adaptation to cognitive and psychological motor skills. The fourth step is self-evaluation, interaction and assimilation. Early learner's classroom action research, such as autonomy, interface interaction and content assimilation, is to get relevant data of their participation in game [1].

In 2014, the By project team pointed out that the theory and practice of preschool children's computer game design is very short and shallow, and the design and development of this type of game is still in the initial stage [2]. Reviewing the research status of the subject at home and abroad, it is believed that there are still many shortcomings, which are mainly reflected in the following aspects.

First of all, the combination of education and entertainment is hard. The combination of education and entertainment of games is not very good. In 2016, Kirova point- 
ed out that the development of educational games often focused on the design of game factors instead of combining learning [3]. The results of the Fowler team's test on some specific educational games in 2013 also showed that many games were used as a tool to support information practice in education, similar to the digital exercise book, but did not make good use of the powerful function of an interactive free context media of games [4]. The educational games in China are more and more common in the combination of game and education. A large number of educational games are still based on the direct transfer of book knowledge, and the related knowledge is directly grafted to the content of the game, in which the monotonous answer is the most used. As a result, the players can easily distinguish which part is the content of games and which part is the content of education. The educational traces that exist in educational games which are not closely related to the plot of the game not only weaken the entertainment of the game, but also affect the learning effect.

Secondly, the game is lack of hierarchy. Preschool children have their own personality characteristics, and each child's existing knowledge base is different. However, the current preschool education game software basically fails to take into account of this, but they are all large and unified game design concepts. According to the theory proposed by Macewan in 2015, if the problem is located in the current level of development, the learners will feel uninteresting, which is not conducive to the development of the learners' intelligence and the motivation of learning. If the problem is located in the region of the recent development zone, the learners will feel very depressed and even have a learning weariness [5]. Only when the problem is located in the recent development zone can the development of students' intelligence be effectively promoted and the learners maintain high learning enthusiasm. Therefore, the development of preschool children's educational game software is also essential.

Thirdly, it lacks localization of the game. Some small game websites in China are investigated and analyzed. First of all, the description of the interface and the sound localization are insufficient. The majority of the network preschool children games are Korean games, the interface of the text is basically Korean or English, and the voice prompts are also foreign languages. Basically adults cannot understand the rules of the game, only by groping for the game. Secondly, the localization of character design and scene design is missing. Many cartoon character designs and scene designs in the game are branded with exotic culture.

Finally, the game ignores the psychological characteristics of preschool children. Lee pointed out in 2013 that the most important feature of an influential program is [6], the content that is suitable for audiences' psychological age. As a special age group, preschool children have special psychological characteristics of children in this age stage, but most of the preschool children education game software has not paid much attention to the psychological characteristics of preschool children, such as the lack of timely feedback and the construction of scaffolding. Preschool children usually don't know many words. They should be accompanied by pictures, voice and other instructions, but many preschool children do not take this into account. 


\section{$3 \quad$ Method}

\subsection{Research method}

In order to further study this topic, the author applies the combination of quantitative research and qualitative research. Specific methods include literature survey, questionnaire survey, case production and interview.

Literature survey method: by collating relevant information in the library and looking up the relevant information on the web site of China, we collect the treatises and papers on the theories and practices related to educational games both at home and abroad, and also acquire the theories related to the preschool education. On this basis, the research achievements of domestic and foreign scholars on educational games and early childhood education are introduced, so as to provide theoretical basis for our research.

Questionnaire survey method: based on a questionnaire survey of preschool children's cognition attitude towards computer games, this paper analyzes the feasibility of computer games entering preschool education. Due to the particularity of preschool children's age, we conduct a questionnaire survey on some preschool teachers and some children's parents to understand the cognitive attitude of preschool children to computer games from the side.

Case making method: according to the needs of preschool children, select appropriate curriculum content and conduct case making. In the following section, the whole design process of preschool children's appropriate educational game development is introduced in detail.

Interview method: through interviews with preschool teachers, some problems in preschool education and the needs of preschool children in the course of preschool education are understood, and the entry point of education games into pre-school education is sought. After a trial in preschool children's teaching, interviews with preschool teachers are conducted to explore the problems and improvement methods in the process of using games.

\subsection{Requirement analysis}

As a result of the influence of traditional educational concept, people have approbate in the form of computer games, but the preschool children are young that the body and mind are not mature, and there are some bad online games in society, which really affect the healthy growth of many children. As a result, parents and preschool teachers are still in a state of doubt about the combination of computer games and education.

The preschool children education game is still a new research field in China. In order to better understand the knowledge and attitude of preschool children to computer games, we make a questionnaire to understand the attitudes and views of preschool children, teachers and parents on educational games, so as to better understand what kind of tourism children need. 
Because of the age characteristics of preschool children, we cannot directly investigate them. Therefore, we visit some preschool teachers and some parents of preschool children to investigate the cognition of computer games for preschool children. A total of 120 teachers' questionnaires are issued, and 87 copies are recovered. 330 questionnaires are distributed to parents, and 256 are recovered. The investigation is mainly in the form of choice question, divided into single choice and multiple-choice. In order to have a more comprehensive understanding of the new form of learning in educational games, the last choice of the questionnaire uses the open form to allow teachers and parents to add their own views.

\subsection{Analysis of the characteristics of preschool children's educational games}

The characteristics of preschool children's educational games mainly include the following five aspects:

The first one is interesting. It is the primary factor for game designers to consider. If the game is not fun, children can't be attracted to games, and good teaching effect is impossible.

The second is objective. The effect of preschool children's more explicit goals is better. Therefore, objective is one of the characteristics of preschool children's educational games. The design of picture, content, voice and so on should be focused on this goal.

The third is imaging. From the character design, we should use the cartoon characters that the preschoolers are pleased to see in the feedback design. When the children do well, they should not use the written word "you answer right" or simply say "you are good" with the sound, but should be with the action or the picture of the person. For instance, when children do well, characterizations that express happy such as laugh and dance are used to give feedback.

The fourth is interactive. Preschool children are more interested in dynamic things than static ones, so the interaction of games is essential. For example, a Romania game "jump school" is about a clean mouse hole in the ground. A group of music loving "art mice" lives in the cave and sets up an interesting band. In the game, no matter where the mouse is clicked with the mouse, the different notes will be sent out if the function button is clicked, and the song can also be played with the melody of its own improvisation. This game will play the most active role in human-machine interaction, which fully demonstrates the importance of good interaction to the game. With this game teaching method, children will naturally be interested in music.

The last one is simple. In view of the characteristics of preschool children's cognition, the plot of the game should be relatively simple, and the relationship between the characters should not be too complicated. It is best to select the traditional classic stories or science fiction stories as the subject, and the characters can also select the cartoon characters which children are pleased to see. In the knowledge study, it should be based on the characteristics of the children. On the basis of visualized props, through the imaging perception extending to the abstract and logical knowledge, it is unnecessary to design the problem too hard, but step by step. 


\subsection{Game design framework}

The design of the game generally includes the elements of planning, procedure, art and sound effect, and the design of preschool children's educational games, in addition to the contents of the above game design, also includes the content of the teaching design. The general process of preschool children's education game development is as follows: the first is the analysis stage, then the game design, the material making, programming and application, and the final is test and evaluation, to enable the learners to try and evaluate in the learning process, find out the shortcomings, make the modification, and form the final product. To design preschool children's educational games, we should start with the teaching design, determine the learning goal, the learner and the learning content as the "navigation mark", guide the whole design process, and ensure the education nature of the preschool children's educational games. And the whole design framework is centered on the design of the game environment, and the design of the elements in the learning environment for preschool children's education games is carried out to ensure the playfulness of preschool children's educational games. The educational game design framework for preschool children is shown in Figure 1.

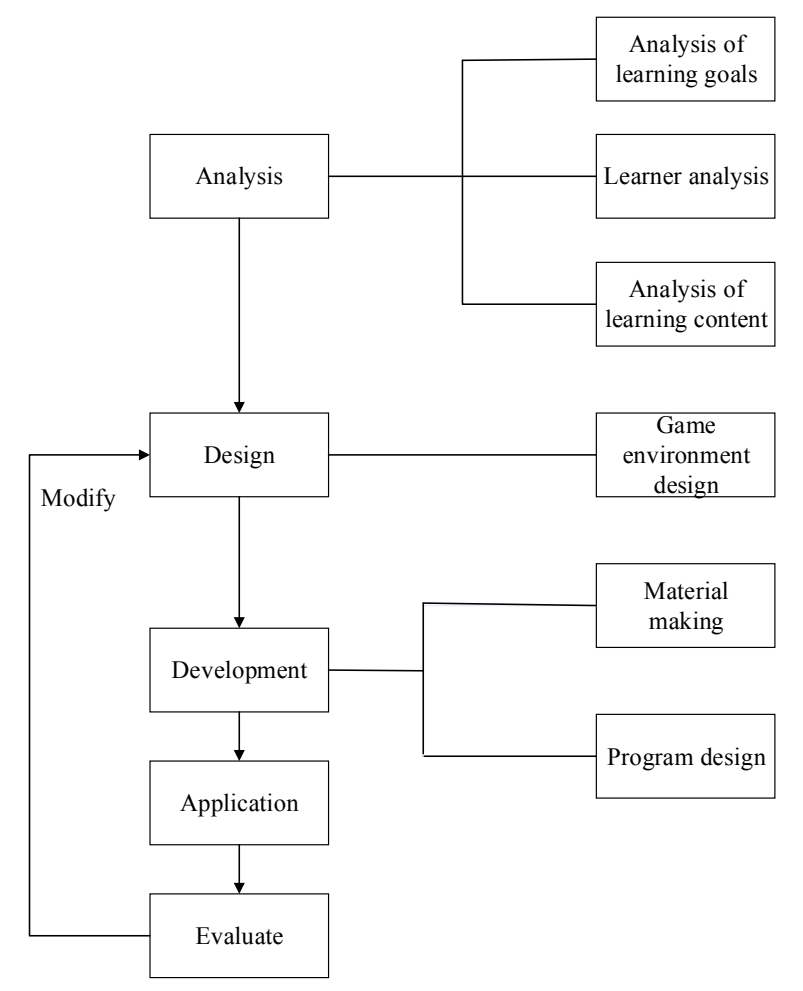

Fig.1. Design framework for preschool children's education games 


\subsection{The game design of "Little girl crossing the river"}

The game logic structure describes the complete execution process and execution mode of a game task. The game logic defines the jump conditions between the various nodes and the cycle path of the game execution. It plays a guiding role in game design and program development. The running logic of "Little girl crossing the river" game is shown in Figure 2.

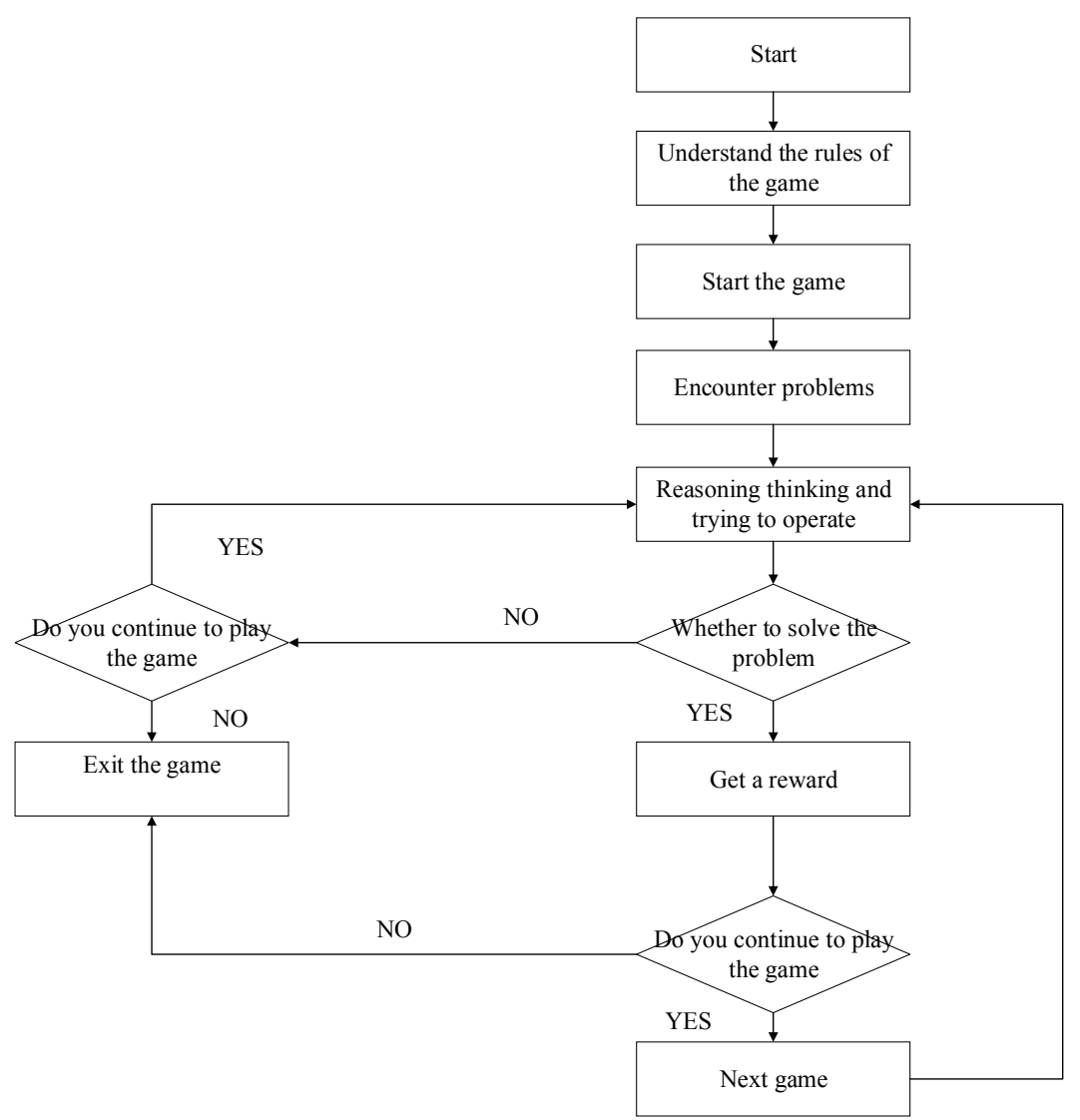

Fig.2. Game running logic diagram

"Little girl crossing the river" game background is that the grandmother is sick, little girl goes to visit her, but the bridge lacks a few pieces of board on the river. It requires the child to find the rule of the pattern on the bridge, and then use the correct board to make up for the bad place to help the little girl across the river to visit her grandmother. In the game of "Little girl crossing the river", preschool children can repair the bridge surface by observing the rule of graphic arrangement. In the process of the game, it contains the cultivation of cognitive ability of color, shape and quantity, and the cultivation of observation ability. 


\section{$4 \quad$ Result}

\subsection{Demand analysis results}

By questionnaire, only $11 \%$ of the children were not interested in computer games among the investigated, and in those groups that did not like to play video games, the proportion that boys did not like to play video games was far less than that of girls. The attitude of preschool children to computer games is shown in Figure 3.

In response to "Have you ever played computer games", 10\% chose "often", and $41 \%$ chose "occasionally", that is, more than half of the students played computer games. The result of "Have you ever played computer games" is shown in Figure 4.

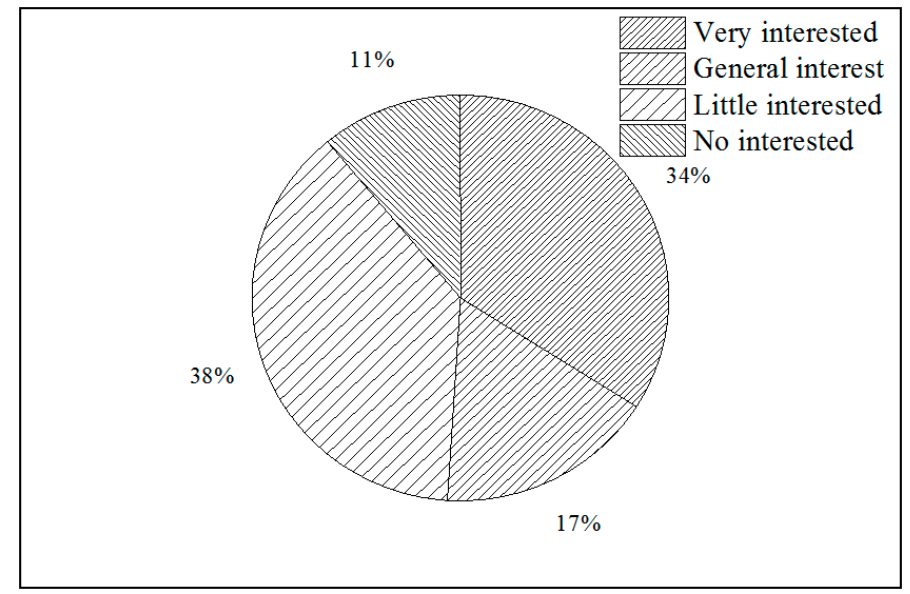

Fig.3. Preschool children's attitude towards computer games

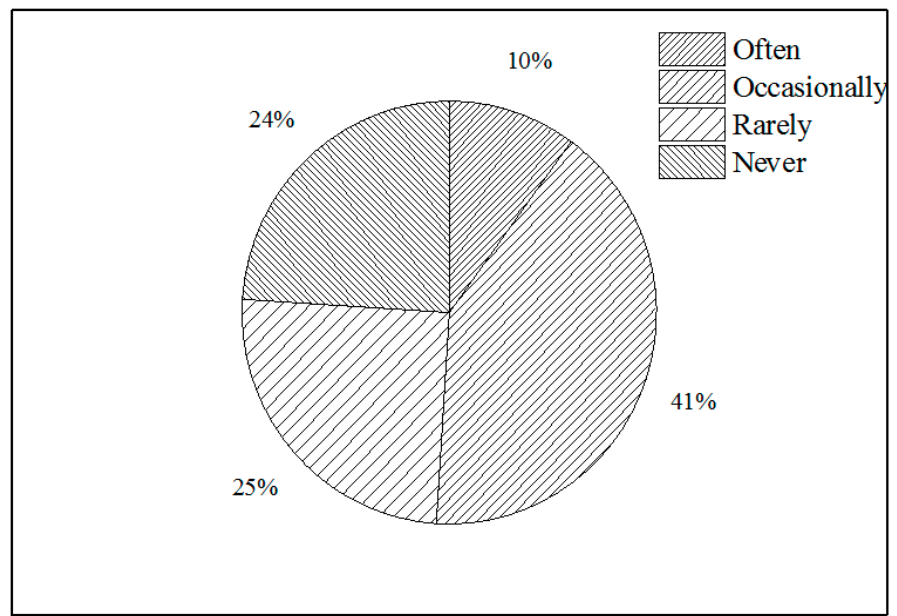

Fig.4. Have you ever played computer games 
Teachers and parents have a certain degree of recognition in the application of computer games to preschool children's education. The teachers surveyed generally believe that computer games will help the teaching. Among them, 20\% of them think that it is of great help, but only $1 \%$ of them think that there is no help. It seems that they have a high degree of recognition for computer games. The teacher's view of whether computer games can help teaching is shown in Figure 5.

Parents' recognition of computer games applied to teaching is still very high. $63 \%$ of parents agree to properly use computer games in teaching. But at the same time, parents also worry about the application of computer games to preschool education. Parents' views on computer games applied to teaching are shown in Figure 6.

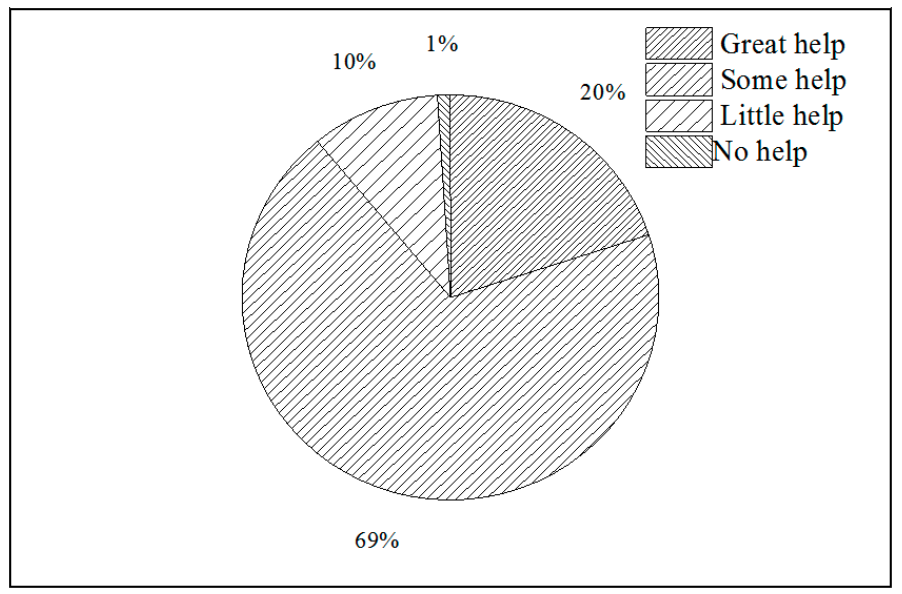

Fig.5. The teacher's view of whether computer games can help teaching

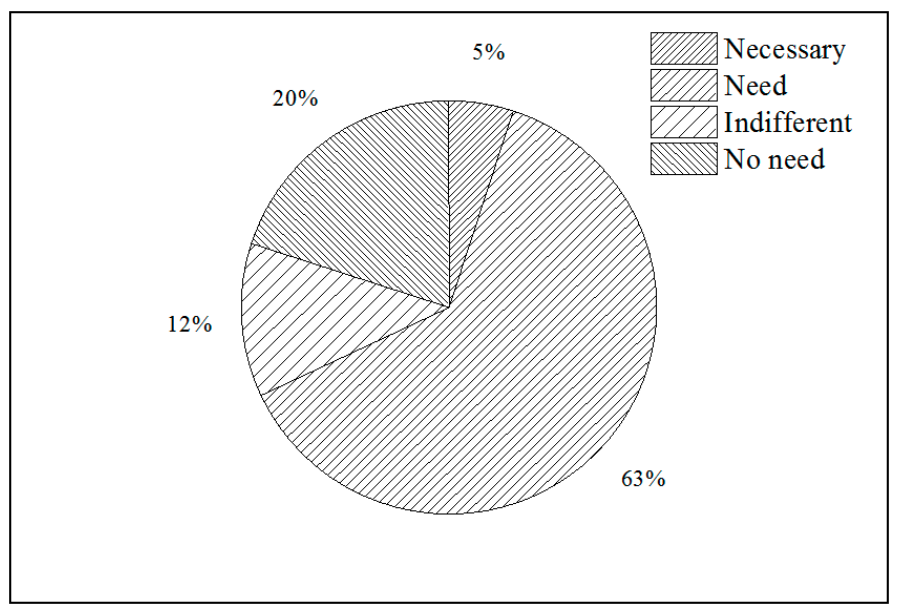

Fig.6. Parents' views on computer games applied to teaching 
Through the investigation and analysis, it is not difficult to find the attitude of preschool children, teachers and parents to educational games, and also have some thinking about the development of preschool children's educational games. Preschool children have a lot of interest in computer games, and teachers and parents are willing to apply computer games to preschool children's education. Therefore, facing computer games, we do not dare it when we talk about it, nor do we ignore them, and cannot be afraid of their negative impact to simply chase and block them. The practice also shows that it is not feasible blocking and besieging alone. As long as the educators correctly understand and guide them properly, they can not only avoid the negative effects of online games, but also make full use of their educational functions to promote the development of preschool children. Therefore, it is completely feasible to let health education game enter the children's life. The country also provides a broad development space for educational games, and what now lack are the qualified educational games suitable for children's taste.

\subsection{Application result of "Little girl crossing the river" game}

After the development of the software, Jin Baobao kindergarten teachers are asked to use the software. In the trial, we first of all explain the teaching purpose and using method of games for middle three class children, a total of 30 students, and then let the students to play and learn, and we conduct guidance and observation in the process of learning. In order to compare the effect of traditional teaching form, we choose the middle two classes in the kindergarten, with a total of 28 students, and ask the same teacher to use traditional teaching methods to focus on the cognitive characteristics of the middle class children. The traditional teaching mainly adopts teaching methods combining teachers with pictures to teach children in this class. The classroom is observed, and then the behavior of two classes of children is observed through preschool teachers, and the teaching effect is compared.

Through the observation of children's performance in class, we found that about $90 \%$ of children's attention in class three can be focused on classroom teaching, only a small number of young children paid attention to other things for a while. However, many students in class two have distraction that they need teachers to keep reminding and emphasizing the children's compliance with the class order. This shows that the use of educational games in teaching can significantly improve children's attention. At the same time, we can also find that, no matter the number of speakers or the number of speeches in class, the situation of class three is obviously better than that of class two. It indicates that, in the use of educational games, the teaching normal mode can obviously improve the enthusiasm of children to participate in the classroom teaching.

After class, some children in class three are surveyed. Almost all children clearly indicated that they liked this class very much. Through interviews with preschool teachers, we also learned that many children in class three after class asked "when can we play games in class?" It can be seen that this mode of educational games is welcomed by children. In order to compare the effect of the traditional teaching form, we organize 8 people in the kindergarten and the backbone teachers to listen and evaluate 
the class in the experimental class and the reference class. The results show that the educational games have achieved good results.

Teachers generally affirmed the effectiveness of this teaching mode in improving children's self-inquiry ability and organizing children's full participation in teaching. At the same time, this teaching mode has great advantages in attracting children's attention and enthusiasm. Teaching teachers generally believe that the teaching model adopted in this class has achieved good results. In the meanwhile, the content and characteristics of the game itself meet the requirements of teaching and can be well applied to teaching.

\subsection{Discussion on the design of children's entertainment software}

In the course of the education experiment in the kindergarten, by observing the classroom teaching and listening to the feedback of children and preschool teachers, some problems that should be paid special attention to in the design of preschool children's educational games are summed up:

Firstly, preschool children's educational game design should be combined with preschool education goals. The design of preschool children's educational games should be in accordance with the requirements of The Guidelines for Kindergarten Education, and the requirements of the nursing goals put forward in the Regulations of the Kindergarten Work should be fully implemented. In the use of preschool education games, the development of children's emotion, attitude, ability, knowledge and skills should be promoted from different angles. This is the ultimate goal of teaching by using educational games. The design of picture, content, voice and so on should be focused on this goal.

Secondly, preschool children's educational game design should give full consideration to the physiological and psychological characteristics of preschool children. A good preschool education game should consider the physiological and psychological characteristics of the target age children. Preschool children's educational games must conform to the psychological characteristics of preschool children. For example, preschool children like cartoon, dynamic character features and lively and cheerful voice. The simplicity of educational game design for preschool children cannot be ignored in terms of operation. The rules and operation methods of the games used by preschool children cannot be complex; otherwise it will directly affect the children's experience. Even if the content is good, the teaching effect will be discounted.

Thirdly, preschool children's educational game design should cooperate with preschool teachers. In order to design good educational game software, the designer should not only have a certain teaching design ability, the corresponding knowledge of the psychological motivation of the professional knowledge game, the rich imagination, the skillful computer operation skills, the familiarity with the business game software and so on, but also have to cooperate with the front-line teachers. Then we can design a practical educational game software that accords with the needs of children and accords with the needs of teaching.

This article only puts forward the design scheme and design case of preschool education games, and tries it in a small scope. In the follow-up study, we will make a 
further empirical study on the design game, and keep paying attention to the design of children's game to fill the shortage of this study, and expect to produce certain effect on the kindergarten curriculum teaching. At the same time, we hope that we can cooperate with kindergarten teachers and professional game development teams to develop high-quality preschool education game products and finally push to the market.

\section{Conclusion}

Through the study of preschool children's educational game design, this paper tries to explore the balance point of educational games and preschool children's education. Some research work has been carried out in the following aspects: first of all, the general process of the design and development of preschool children's educational games is expounded. From the point of view of games, educational games belong to the category of computer games, so they follow the general rule of computer game development. From the point of view of education, the educational character of educational games is the biggest characteristic that is different from the general game. Therefore, in the process of design and development, it is necessary to integrate the content of teaching design and try to balance the educational and playfulness of the educational game. Secondly, according to the element model of preschool children's educational games, the suitable kindergarten curriculum is selected and the preschool children education game "Little girl crossing the river" is developed by software design. On the basis of practice, the whole design process of preschool children's educational game development is introduced in detail. The main steps and key technologies involved in the conception, design, development and application of the case are described in detail, and the game design is improved on the basis of the analysis of the application effect.

In China, the research on the design and development of preschool children's educational games is still in the exploration stage, and many theories and techniques are not mature or perfect. The research done in this paper is only a part of the study. There are still a lot of places to be further improved. In preschool children's educational games, to consider attracting children's attentions, the game design takes into account more of the game nature. For instance, the game design emphasizes the game activity of mending the bridge, but does not give too much hint to the knowledge content, so it is not conducive to the attention to the new knowledge of the game in the process of learning. In preschool children's education games, because of the strong knowledge of learning content, there are more educational components in the game design, but the consideration of the game is not enough. In addition, due to the hurry of time, the trial users of games are limited to the Jin Baobao kindergarten, which is familiar with the author. As a result, the trial results are relatively limited. In subsequent research, we need to expand the trial scope of the game, so that the effect of the trial is representative, so as to guide the improvement of preschool education game more effectively. 


\section{$6 \quad$ Reference}

[1] Boyd, B A., Hume, K., Mcbee, M T., et al (2014). Comparative Efficacy of LEAP, TEACCH and Non-Model-Specific Special Education Programs for Preschoolers with Autism Spectrum Disorders. Journal of Autism \& Developmental Disorders, 44(2):366-380. https://doi.org/10.1007/s10803-013-1877-9

[2] By, B J., Grace, R., (2014). Review of early childhood parenting, education and health intervention programs for Indigenous children and families in Australia. Canberra Closing the Gap Clearinghouse, 6(7):1-5.

[3] Kirova, Anna., Massing, Christine., Prochner, Larry., Cleghorn, Ailie. (2016). Shaping the "Habits of Mind" of Diverse Learners in Early Childhood Teacher Education Programs through Powerpoint: An Illustrative Case. Journal of Pedagogy, 7(1):59-78. https://doi.org/10.1515/jped-2016-0004

[4] Fowler, S A., Thomas, D V., Tompkins, J., et al (2013). Strategies for Enrolling Traditionally Underserved Families in Early Childhood Education Programs. Early Childhood Research \& Practice, 15(2): 8.

[5] Macewan, A. (2015). Early Childhood Education, Economic Development, and the Need for Universal Programs: With a Focus on New England. Economics Management \& Financial Markets, 10(1-2):122-144.

[6] Lee, G L. (2013). Re-emphasizing Character Education in Early Childhood Programs: Korean Children's Experiences. Childhood Education, 89(5):315-322. https://doi.org/10.1080/ $\underline{00094056.2013 .830907}$

\section{$7 \quad$ Author}

Xicai Li is with the Moscow Arts College of Weinan Normal University, Shaanxi, China.

Article submitted 28 February 2018. Final acceptance 05 May 2018. Final version published as submitted by the author. 